\title{
Telepsychiatry: A solution for the unmet mental health needs of the transitional age population
}

\author{
Michael Tsappis* \\ Division of Adolescent/Young Adult Medicine, Department of Psychiatry, Boston Children's Hospital and Department of Psychiatry, Harvard Medical School, \\ Boston, Massachusetts, USA
}

\begin{abstract}
In many disciplines people between 16 and 25 years of age are termed "transitional age." This age group is at high risk as a result of existing and new onset mental health disorders and substance abuse. Creative solutions are needed to minimize barriers to new care or interruption of existing care for this population. Those who move away for college or other pursuits are particularly vulnerable. It is vital to mitigate risk of underachievement, social impairment and death. This paper presents a representative case to illustrate an unmet need in a transitional age patient. A brief review of telepsychiatry is provided demonstrating evidence in support of its acceptability and effectiveness for providing mental health care. Telepsychiatry is presented as a rational solution to meeting the mental health care needs of the underserved transitional age population.
\end{abstract}

A 19 year-old woman presents for outpatient psychiatric care. Her mother accompanies her to the first visit and provides much of the initial history. The patient is anxious, slightly tremulous and sleeping poorly. She has been on fluoxetine for over a year. The current dose is 40 mg but because of her heightened anxiety her mother has been giving her $80 \mathrm{mg}$ daily for the last week. Anxiety has since increased. Social stressors include parental divorce, a somewhat alienated relationship with father and peer relational problems. She does not drink or use drugs. There are no major medical concerns. She is completing the first year of a rigorous undergraduate program at an urban college 45 minutes from her hometown where her mother, stepfather and younger sibling still live. Moving from home into the city is the greatest stressor. She has been close with mother and relied on her for soothing and guidance throughout development.

Treatment consisting of hourly psychotherapy every two weeks and medication management is initiated. The fluoxetine dose is reduced to the previous $40 \mathrm{mg}$. Clonazepam is added as needed and is used responsibly by the patient. The first part of the therapy includes adjustment to the loss of the previous therapist who had left her practice. During the next three years there is a focus on identity development, separation and individuation. She grows into her adult role, develops independent ability to cope with stressors with lessening dependence on maternal soothing, forms new relationships, challenges schemas inherited from her mother and is able to comfortably act without concern for maternal approval. Her anxiety improves. She is eventually weaned off of the fluoxetine. She continues to use the clonazepam as needed but not frequently. Through the course of treatment guidance and support is provided as she experiences the loss of a close friend, a break up with a long term boyfriend, the passing of her maternal grandmother, an elective termination of pregnancy, the stressors of her academics, college graduation and then the illness and passing of her mother. Though meaningful progress is made in the therapy, she has remained close and somewhat dependent on her mother. The stress of this loss is great.
Support and therapy is provided through her grieving process. She meets a new partner who she will eventually marry. Guidance is provided on forming and maintaining meaningful adult relationships, living independently and then cohabiting with her partner. She is able to develop a vision for a future training and work that aligns with her partner's. They apply to graduate schools in their respective fields and are accepted. Her graduate school is one thousand miles away and in a different state. Treatment must end at a time when she must now adjust to a move to a new region with subtle but present differences in cultural norms. There are new routines. She is separated from much of her support network. She will transition back into rigorous academic study. She will prepare for a wedding with constant awareness that her mother will not be there to help plan for the wedding; and that her mother will not attend her wedding. The need for treatment remains.

This case demonstrates a common challenge faced when caring for patients in the transitional age group of 16 to 25 years. It is a vulnerable group who are adapting to many new rights and responsibilities. During this time they are launching from their families of origin and often moving away from supports and previous health care providers. Decisions are made that impact future education, work and role in society. Adult relationships are formed. These stressors combined with not yet developmentally mature executive functioning abilities place this group at high risk for mental health and related behavioral disability.

Correspondence to: Michael Tsappis, Division of Adolescent/Young Adult Medicine, Department of Psychiatry, Boston Children's Hospital and Department of Psychiatry, Harvard Medical School, Boston, Massachusetts, USA, Tel: 617/355-7181; E-mail: Michael.Tsappis@childrens.harvard.edu

Key words: college age, mental health, telepsychiatry, transitional age

Received: August 13, 2015; Accepted: September 15, 2015; Published: September 18, 2015 


\section{The transitional age population and demand for mental health services}

There are over 43 million individuals in the transitional age in the United States [1]. This group experiences the highest prevalence of mental disorders of any age group [2]. Up to seventy-five percent of all lifetime mental health disorders have an onset by 24 years of age [3]. They have the highest rate of drug and alcohol use and are the most likely to be diagnosed with a substance use disorder [4]. People in this age group are at the highest risk for onset of major mental illness such as Schizophrenia, Schizoaffective disorder and Bipolar Disorder [5]. The average age of onset and presentation for both Anorexia Nervosa and Bulimia Nervosa is during the transitional years [6]. This is an age group with a high likelihood of needing mental health care.

What is the effect of untreated mental disorder at this life stage? There is suffering from the direct effects of the disorder itself as well as from resultant functional impairments. Untreated college students experience a higher rate of withdrawal from college [7]. Those who do not withdraw may achieve below their potential [8]. An increased risk of unemployment in young adults has been linked to mental illness such as depression [9]. The ability to form and maintain healthy relationships may be compromised. There is evidence of increased high-risk sexual behavior and corresponding risk of sexually transmitted infections, HIV and unplanned pregnancy [10]. There is a risk of death. Suicide is the second leading cause of death among transitional age individuals [11]. Conditions described above such as anxiety, depression, impulsivity, substance use, eating disorder, isolation from supports and barriers to accessing health care are all risk factors for suicide [12].

Most high school graduates will attend college [13]. As many as 250,000 students leave their home state to do so [14]. This presents a particular challenge to the patient and provider. As in the case presented above, many in this group will need ongoing mental health care. Those with an established provider will be at risk of losing a previously meaningful treatment relationship and face the challenge of "starting from scratch" with a new provider. Others without prior mental health care will need to negotiate the complex landscape of acquiring new mental health care services without having prior knowledge of the system. The new location of residence is temporary. Students are away during the school term but may be home for breaks, holidays and summer. This pushes a decision between care close to home and family of origin or near school and away from supports. In either case there are extended periods of geographic separation from the health care provider. Those who enter college after having received effective multidisciplinary care for eating disorder are separated from their treatment team and enter a setting where there is a high risk for relapse. Ultimately, most college and graduate students with a mental health concern do not seek or receive health care [15].

\section{Telemedicine allows for appropriate care}

Telemedicine holds promise for addressing the needs of this high risk, vulnerable population. Telemedicine allows for the provision of health care services that would ordinarily occur face to face over electronic media. Such services may include those provided over voice telephone, video telephone, email, text messaging and any other emerging technology platform [16]. Psychiatry is particularly suited to telemedicine. There is a recognized need to extend quality care to underserved populations. Quality psychiatric care can often be provided without the need for physical examination of the patient or use of diagnostic implement [17]. Although the necessary technology and acceptance for telepsychiatry exists, the current healthcare regulatory environment does not yet allow for its routine use.

An urgent consideration of the role of interactive care over video telephone has been called for since the very earliest reports on the subject [18]. Balancing such enthusiastic promotion has been a number of commonly cited reservations. There were early questions about equipment cost and maintenance, reliability of the technology and what to do in case of lost connection, how to maintain medical records and to execute prescriptions $[17,19,20]$. The now widespread availability of the Internet has allowed for encrypted video telephone service between personal computers, tablets and telephones. Modern electronic medical record and prescribing software has eliminated prescribing and documentation concerns.

Telepsychiatry offers a satisfactory health care experience. Positive satisfaction has been consistently demonstrated in adult patients, child and adolescent patients and their families as well as providers [20-24]. In 2001 Tracy Williams [25] published an informed criticism of Telemedicine satisfaction studies noting common weaknesses of uncontrolled study design, small sample size, lack of standardized rating scales, response bias and patient selection bias. A subsequent head to head study controlled for cost, travel, access to care, wait time and service provider. Eliminating many factors that would make telepsychiatry more favorable still resulted in a small magnitude and statistically insignificant trend toward preference for in person care [26]. Some patients may feel more comfortable with telepsychiatry that in person care. One report described a 15 year-old girl who had refused previous referrals to treatment but agreed to a telepsychiatry visit. She reported feeling more comfortable in front of a monitor than with a real psychiatrist [27].

The quality of care is not compromised by use of video telephone $[23,28]$. Patients receiving care via telepsychiatry have been shown to experience clinical improvement commensurate to those receiving face-to-face care [29]. Some clinical problems might only be able to improve with creative solutions like telepsychiatry. Norman Paul [30] reported on the treatment of two adolescent siblings, one admitted to the hospital for depression.Both parents were military personnel stationed 4500 miles apart. A family interview conducted by satellite telecommunication was demonstrated as pivotal to the positive outcome described in both children; an encouraging report when considering the problem of patient mobility and geographic separation.

The psychiatric encounter must change if care is provided by telepsychiatry. Psychiatry is grounded in a respect for the importance of the provider-patient relationship. That relationship is defined by implicit and explicit interactions. There are unspoken but meaningful rituals and routines that are integral to the evolving relationship. The impact of technology and a lack of direct human contact must be considered [31]. Is society ready for healthcare provided in a virtual environment? The lack of in-person contact with telepsychiatry has been labeled "morally troubling" in one commentary [32]. The primary question is whether the ability of the participating parties to experience some aspect of each other's "whole selves" is lost in a virtual encounter. The answer is almost certainly yes. But what is lost when a long-term treatment relationship must be terminated prematurely or when there is no suitable care available except by telepsychiatry?

\section{Current obstacles for expanded use of telepsychiatry}

The current medical regulatory and policy landscape in the United States does not allow for routine use of telepsychiatry. An interest 
in providing this service demands consideration of state licensure, malpractice coverage, insurance reimbursement, and privacy requirements [33].

The site of care in telepsychiatry has been arbitrarily set as the patient's physical location and not the provider's. As a result, the provider must be licensed in the jurisdiction of the patient's location. A psychiatrist with patients graduating high school and moving off to college, graduate school or other pursuits in many states across the country would have to be independently licensed in each individual state. The licensing fees and variable continuing education requirements would be prohibitive [34].

There are alternative methods of determining jurisdiction over licensing and locus of care [35]. Most European Union countries license physicians at the national level and allow for reciprocity over national borders. A National licensing process may need to be developed in the United States. Such a process might transfer physician licensing to the national level, allow for reciprocity between states, create a telemedicine addendum to local state licensing, mandate that care be defined as occurring at the location of the provider or define the location as virtual and create a separate license for the provision of telemedicine. Third party payers could be required to pay for telepsychiatry services without exclusions. Medical malpractice coverage could be modified accordingly.

\section{Conclusion}

The transitional age population represents a group in particular need for mental health care service. The prevalence of mental and substance use disorders is higher than at any other time in life. The risk of exacerbation of previously existing disorders, new onset of illness, underachievement, relational impairment and suicide is high. Telepsychiatry is a rational solution to the care needs of this unique and vulnerable population. It has been established as a satisfactory, effective, safe and reliable platform for healthcare delivery. Acceptability for this form of care is expected to grow even more as younger individuals increasingly prefer use of Internet based technology for activities previously occurring in person. Telepsychiatry allows for continuity of care for an increasingly mobile population. Outdated licensure, malpractice and reimbursement policies are limiting the ability to service this high-risk population. The early sense of urgency to make this resource available must return if we are to succeed in meeting the health care needs of transitional age populations and other underserved groups.

\section{Acknowledgements}

This work is supported in part by the Leadership Education in Adolescent Health Training grant T71MC00009 from the Maternal and Child Health Bureau, Health Resources and Services Administration. The author would like to thank Elizabeth R. Woods, MD, MPH for her critical review of the manuscript.

\section{Disclosure}

The author's spouse is employed part-time by a private telemedicine company to provide psychotherapy through a telemedicine platform. This is reported but not regarded as a conflict of interest.

\section{References}

1. United States Census Bureau(2013) Age and Sex Composition in the United States: 2012. [online] Available at http://www.census.gov/population/age/data/2012comp. html [accessed 7 August 2015].
2. Newman DL, Moffitt TE, Caspi A, Magdol L, Silva PA, et al. (1996) Psychiatric disorder in a birth cohort of young adults: prevalence, comorbidity, clinical significance, and new case incidence from ages 11 to 21. J Consult Clin Psychol 64: 552-562. [Crossref]

3. Kessler RC, Berglund P, Demler O, Jin R, Merikangas KR, et al. (2005) Lifetime prevalence and age-of-onset distributions of DSM-IV disorders in the national comorbidity survey replication. Arch Gen Psychiatry 62: 593-602.[Crossref]

4. Arnett JJ (2000) Emerging adulthood. A theory of development from the late teens through the twenties. Am Psychol 55: 469-480. [Crossref]

5. Gogtay N, Vyas NS, Testa R, Wood SJ, Pantelis C (2011) Age of onset of schizophrenia: perspectives from structural neuroimaging studies. Schizophr Bull 37: 504-513. [Crossref]

6. Favaro A, Caregaro L, Tenconi E, Bosello R, Santonastaso P (2009) Time trends in age at onset of anorexia nervosa and bulimia nervosa. J Clin Psychiatry 70: 1715-1721. [Crossref]

7. Gallagher R (2014). National survey of college counseling centers. International Association of Counseling Services, Inc. [online] Available at: http://www.iacsinc.org International Association of Counseling Services, Inc.

8. Mortier P, Demyttenaere K, Auerbach RP, Green JG, Kessler RC, et al. (2015) The impact of lifetime suicidality on academic performance in college freshmen. $J$ Affect Disord 186: 254-260. [Crossref]

9. McGee RE, Thompson NJ2 (2015) Unemployment and depression among emerging adults in 12 states, Behavioral Risk Factor Surveillance System, 2010. Prev Chronic Dis 12: E38. [Crossref]

10. Elkington KS, Hackler D, Walsh TA, Latack JA, McKinnon K, et al. (2013) Perceived mental illness stigma, intimate relationships and sexual risk behavior in youth with mental illness. $J$ Adolesc Res 28: 378-404. [Crossref]

11. Centers for Disease Control and Prevention (2015)Ten leading causes of death by age group, United States - 2013. [online] Available at: http://www.cdc.gov/ violenceprevention/suicide/statistics/index.html [accessed 7 August 2015].

12. Shaffer D, Pfeffer CR, Bernet W, Arnold V, Beitchman J, et al. (2001) Practice parameter for the assessment and treatment of children and adolescents with suicidal behavior. J Am Acad Child Adolesc Psychiatry 40: 24S-51S. [Crossref]

13. Bureau of Labor Statistics (2015) College enrollment and work activity of 2014 high school raduates. [online] Available at: http://www.bls.gov/news.release/hsgec.nr0.htm [accessed 7 August 2015].

14. Niu S (2015) Leaving home state for college: Differences by Race/Ethnicity and parental education. Res High Educ 56: 325-359.

15. Blanco C, Okuda M, Wright C, Hasin DS, Grant BF, et al. (2008) Mental health of college students and their non-college-attending peers: results from the National Epidemiologic Study on Alcohol and Related Conditions. Arch Gen Psychiatry 65: 1429-1437. [Crossref]

16. Myers K, Cain S, Bernet W, Bukstein O, Walter H, et al. (2008) Practice parameter for telepsychiatry with children and adolescents. J Am Acad Child Adolesc Psychiatry 47: 1468-1483. [Crossref]

17. Baer L, Elford DR, Cukor P (1997) Telepsychiatry at forty: what have we learned? Harv Rev Psychiatry 5: 7-17. [Crossref]

18. Dwyer TF (1973) Telepsychiatry: psychiatric consultation by interactive television. $A m$ J Psychiatry 130: 865-869. [Crossref]

19. Werner A, Anderson LE (1998) Ruraltelepsychiatry is economically unsupportable: the Concorde crashes in a cornfield. Psychiatr Serv 49: 1287-1290. [Crossref]

20. Kopel H, Nunn K, Dossetor D (2001) Evaluating satisfaction with a child and adolescent psychological telemedicine outreach service. J Telemed Telecare 7: $\mathrm{S} 2: 35-\mathrm{S} 2: 40$. [Crossref]

21. Blackmon LA, Kaak HO, Ranseen J (1997) Consumer satisfaction with telemedicine child psychiatry consultation in rural Kentucky. Psychiatr Serv 48: 1464-1466. [Crossref]

22. Doze S, Simpson J, Hailey D, Jacobs P (1999) Evaluation of a telepsychiatry pilot project. J Telemed Telecare 5: 38-46. [Crossref]

23. Elford R, White H, Bowering R, Ghandi A, Maddiggan B, et al. (2000) A randomized, controlled trial of child psychiatric assessments conducted using videoconferencing. $J$ Telemed Telecare 6: 73-82. [Crossref]

24. Simpson J, Doze S, Urness D, Hailey D, Jacobs P (2001) Telepsychiatry as a routine service--the perspective of the patient. $J$ Telemed Telecare 7: 155-160. [Crossref] 
25. Williams TL, May CR, Esmail A (2001) Limitations of patient satisfaction studies in telehealthcare: a systematic review of the literature. Telemed $J$ E Health 7: 293-316. [Crossref]

26. Bishop JE, O'Reilly RL, Maddox K, Hutchinson LJ (2002) Client satisfaction in a feasibility study comparing face-to-face interviews with telepsychiatry. $J$ Telemed Telecare 8: 217-221. [Crossref]

27. Pakyurek M, Yellowlees P, Hilty D(2010)The child and adolescent telepsychiatry consultation: can it be a more effective clinical process for certain patients than conventional practice? Telemed J E Health 16: 289-292. [Crossref]

28. Baigent MF, Lloyd CJ, Kavanagh SJ, Ben-Tovim DI, Yellowlees PM, et al. (1997) Telepsychiatry: 'tele' yes, but what about the 'psychiatry'? J Telemed Telecare 3: 3-5. [Crossref]

29. Kennedy C, Yellowlees P (2003) The effectiveness of telepsychiatry measured using the Health of the Nation Outcome Scale and the Mental Health Inventory. $J$ Telemed Telecare 9: 12-16. [Crossref]
30. Paul NL (1997) Telepsychiatry, the satellite system and family consultation. J Telemed Telecare 3: 52-53. [Crossref]

31. May C, Gask L, Atkinson T, Ellis N, Mair F, et al. (2001) Resisting and promoting new technologies in clinical practice: the case of telepsychiatry. Soc Sci Med 52: 18891901. [Crossref]

32. vanWynsberghe A, Gastmans C (2009) Telepsychiatry and the meaning of in-person contact: a preliminary ethical appraisal. Med Health Care Philos 12: 469-476. [Crossref]

33. McGinty KL, Saeed SA, Simmons SC, Yildirim Y (2006) Telepsychiatry and e-mental health services: potential for improving access to mental health care. Psychiatr $Q 77$ 335-342. [Crossref]

34. Ferrer DC, Yellowlees PM (2012) Telepsychiatry: licensing and professional boundary concerns. Virtual Mentor 14: 477-482. [Crossref]

35. Stanberry B (2006) Legal and ethical aspects of telemedicine. J Telemed Telecare 12 166-175. [Crossref]

Copyright: $(02015$ Tsappis M. This is an open-access article distributed under the terms of the Creative Commons Attribution License, which permits unrestricted use, distribution, and reproduction in any medium, provided the original author and source are credited. 